\title{
PEUTZ-JEGHERS-TOURAINE' SYNDROME (CASE REPORT)
}

\author{
Nishanov F. ${ }^{1}$, Abdullajanov B. ${ }^{1}$, Bozorov N. ${ }^{1}$, \\ Nishanov İ . ${ }^{1}$, Hamidov F. ${ }^{1}$, Mishenina E. ${ }^{2}$ \\ Andijan State Medical Institute, Republic of Uzbekistan ${ }^{1}$ \\ Kharkiv National Medical University, Ukraine ${ }^{2}$
}

\begin{abstract}
Authors present two clinical observations of Peutz-Jeghers' syndrome, which is hereditary and is also called periorificial lentiginosis, multiple polyposis of the small intestine (jejunum mainly) with complications such as intestinal ob-struction intussusception associated with intra-colonic bleeding. The authors concluded that abdominal surgeons should know and remember about Peutz-Jeghers' syndrome, in order to avoid diagnostic and tactical errors and promptly provide expert surgical treatment.
\end{abstract}

Key words: syndrome, emergency surgery, perioficial lentinginosis, intussusception, intestinal obstruction.

Introduction. Peutz-Jeghers-Touraine's syndrome (synonym: periorificial lentiginosis) was first described by J. Hutchinson in 1896. A more detailed description was given by L. L. A. Peutz in 1921. A. Touraine called this condition Lentigo poliposis. H. Jeghers et al. in 1949, described 10 cases of this disorder and emphasized the characteristic triad: polyposis of the gastrointestinal tract, the hereditary nature of the disease, pigment spots on the skin and mucous membranes. Since then, this condition has been described as PeutzJeghers-Touraine's syndrome. This syndrome is found on all continents. Women develop this condition more often than men. The fact that the syndrome occurs in several members of the same family testifies in favor of its hereditary origin. Autosomal dominant inheritance.

Differential diagnosis is carried out with other intestinal tumors: diffuse familial polyposis, juvenile polyposis, multiple and single adenomatous and hyperplastic polyps, pseudo-polyps in ulcerative colitis and Crohn's disease. It is also performed with freckles, senile lentigo, LEOPARD syndrome, hereditary forms of lentiginosis, especially systemic and with mastocytosis. Often the disease is accompanied by cancer of the ovaries and the body of the uterus, breast and pancreas [1-7].

Corresponding Author:

Mishenina Ekateryna, MD PhD,

Assistant of Department of Surgery 1

of Kharkiv National Medical Univeristy, Ukraine.

E-mail: dr.myshenina@gmail.com
These circumstances indicate the complexity and difficulty of diagnosis, as well as the unresolved issues of surgical treatment of PeutzJeghers-Touraine's syndrome.

\section{Case}

Patient B., was born in 19, was urgently admitted to the Department of Clinical Surgery No.3 of Andijan State Medical Institute on 01.06.2009 at $6.40 \mathrm{pm}$ with acute intestinal obstruction.

Presentation: dry mouth, aching and cramping pain throughout the abdomen, nausea, vomiting, gas and stool retention, as well as general weakness and indisposition.

Present history: considers himself ill for a week. She does not associate his disease with anything. According to the parents, 3 years ago she was operated on acute intestinal obstruction at the Department of Pediatric Surgery of the Republican Scientific and Practical Center for Cardiovascular Surgery of Andijan branch. In addition, she was repeatedly consulted by various specialists on the lack of appetite and retardation in physical development and the presence of moderate painful sensations in the abdomen without the proper effect.

On examination: on admission the patient's condition was of moderate severity. There were signs of retardation of physical development. Height $-150 \mathrm{~cm}$, weight $-38 \mathrm{~kg}$. The skin and visible mucous were of pale color. Around the upper and lower lips there was dark brown pigmentation with a diameter of $2-3 \mathrm{~mm}$, lined in 
one row at the border of the transition to the skin of the labial surface (Fig 1).

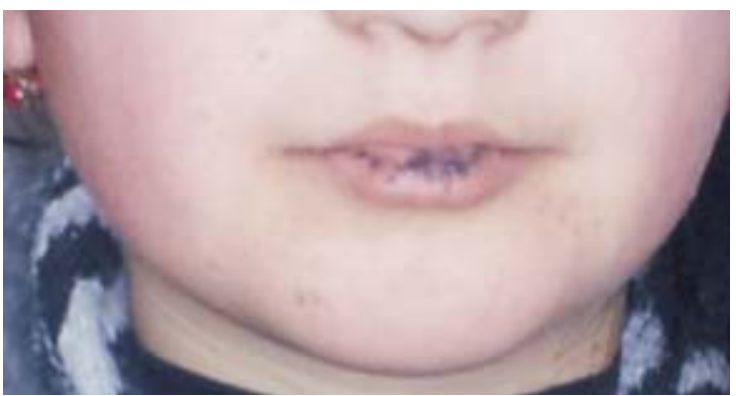

Fig. 1. Patient B. There are dark-brown color pigmentation around upper and downer lips, diameter 2-3 mm, lined one row with border to the lips skin

Tongue was wet and coated. Respiration rate was 20 per minute. Above the lungs: breathing in all departments, no wheezing. Heart rate was 100 beats per minute, blood pressure was 110/ $70 \mathrm{mmHg}$ The abdomen was of the usual form, soft, moderately tender in all departments on palpation. Symptoms of peritoneal irritation were absent. Absence of defecation for 3 days. Flatulence. Urination was without difficulties, regular.

ECG findings: sinus tachycardia. The horizontal position of electric axis of the heart. Hypertrophy of the left atrium and ventricle. Diffuse changes in the myocardium.

Plan radiography of the chest and abdomen: the pulmonary fields are clean, the sinuses are not blocked, the heart and aorta are without abnormalities. There are no signs of free gas in the abdominal cavity; there are single cups of Kloyber. Urine tests did not show any pathology.

Complete blood count: erythrocytes $3.42 \times 1012$, hemoglobin $61 \mathrm{~g} / \mathrm{l}$, hematocrit number 26, CP 0.7, leukocyte count $8.1 \times 109$, ESR $12 \mathrm{~mm} / \mathrm{h}$.

Diagnosis: acute mechanical intestinal obstruction.

The patient underwent complex preoperative preparation (nasogastric probe with gastric lavage, parenteral administration of electrolytes, preventive antibiotic therapy, etc.).

On 01.06.2009 middle-median laparotomy was performed with excision of the old postoperative scar under endotracheal anesthesia after appropriate treatment of the skin with hemostasis along the wound.

Revision of the abdominal organs showed the presence of 3 and 4-cylinder intussuscept (Fig. 2).

After their reduction, the viability of the intestines was preserved. Palpation in these places detected glandular polyps on the pedicle with a diameter of 2.0 to $3.5 \mathrm{~cm}$, which due to the

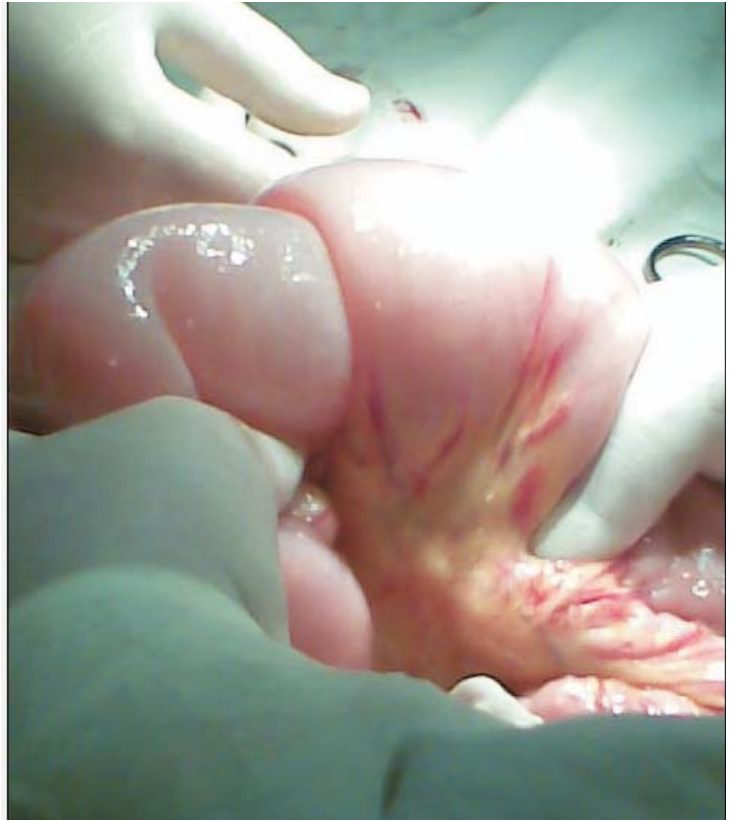

Fig. 2. Sight invagination intestinal obstruction, patient B

overhanging contributed to the formation of intussuscepta. Excision of polyps was performed by longitudinal enterotomy, followed by closure of the bowel defect in the transverse direction, in order to avoid narrowing of its lumen.

Upon further revision, the presence of a multiple polyps was established in the jejunum and single polyps in the ileum with a diameter of 0.71.0 to $3.0-4.0 \mathrm{~cm}$, which could further prevent the passage of its contents and the absorption of nutrients. In addition, enterotomy, excision of polyps and suturing of the defect were performed in 14 places in the same way (Fig. 3).

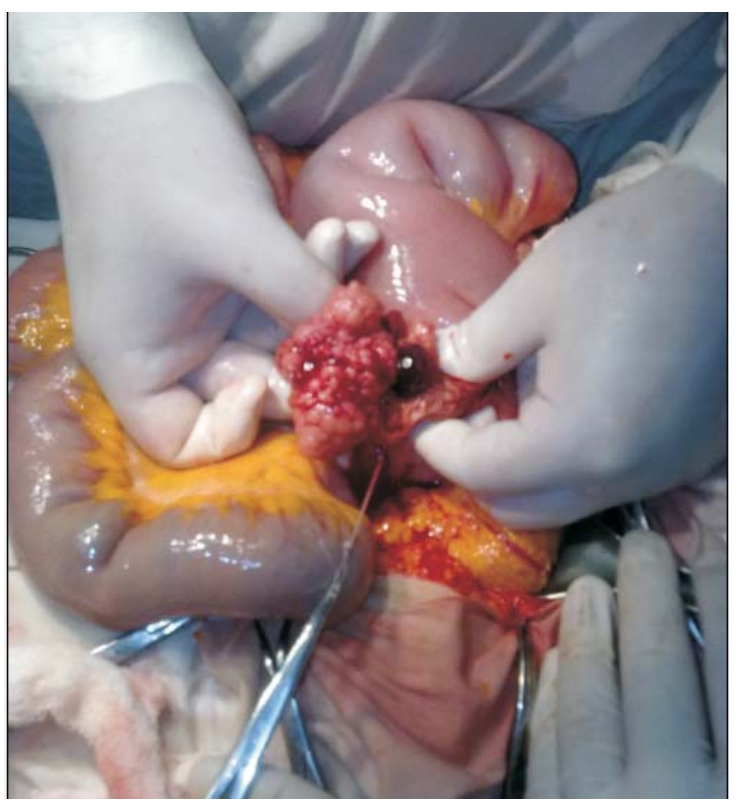

Fig. 3. Sight polyps in enterotomy, patient B 
The patient was administered nasogastroduodenal decompression probe, expansion of the anus according to Payr, as well as thorough reorganization of the abdominal cavity with antiseptic solutions. Drainage of the abdominal cavity was performed for control. Laparotomy wound was closed by layer-by-layer suturing with aseptic dressing.

Gross specimen: glandular-villous polyps of the small intestine in the amount of 27 , with a diameter of $1.5-2.0$ to $3.5-4.0 \mathrm{~cm}$. Of them, 3 polyps had signs of hemorrhage. Histological findings: smooth muscle polyps (Fig. 4).

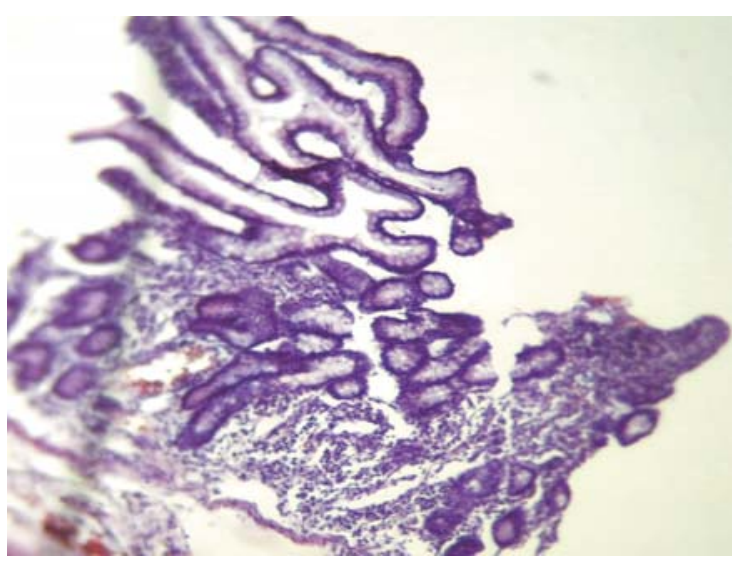

After 1.5 years, we had an opportunity to observe the $2^{\text {nd }}$ case. We present the second observation.

Patient X, born in 1997, was urgently admitted to the Department of Clinical Surgery No.3 of Andijan State Medical Institute on 02/02/2012 at 10.35 am with acute intestinal obstruction, total polyposis of the small intestine.

Present history: from 10/08/2011 to 10/13/ 2011, she was hospitalized for a palpable abdominal tumor projected in the surgical department of the RCEME of the Andijan branch. She was also consulted by an oncologist. As a

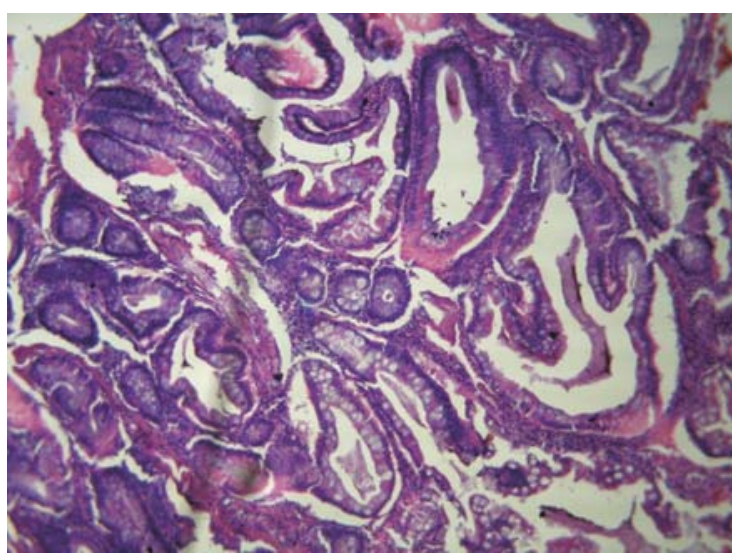

Fig. 4. Micro-preparation of patient B. Polyps tenia of the smooth muscle. Color hemotoxilin eosinum. Enlarged with Leits Biomed microscope. Î B: 40. Î Ê: 10

The postoperative period was uneventful, without complications. On 09.06.2009 the patient was discharged from the hospital in a satisfactory condition. At the same time, the patient was recommended a follow-up every 6 months.

The patient was monitored every 6 months. After 2 years, she gained $15 \mathrm{~cm}$ in height, $17 \mathrm{~kg}$ in weight (height $151 \mathrm{~cm}$, weight 38). She felt well, there were no signs of retardation of physical development. Intestinal function was normal.

After reviewing the literature data and assessing this case, we concluded that there was a triad of signs of Peutz-Jeghers' syndrome: perioral hyperpigmentation, multiple small intestinal polyposis (mostly jejunum) and the presence of intussuscepted jejuno-jejunal obstruction. Moreover, when performing the first operation (reduction of intussusception), its cause was not eliminated. This contributed to the recurrence of acute intestinal obstruction in the form of intussusception, as well as preservation of signs of retardation of physical development and chronic anemia of moderate severity.

This confirmed the complexity of diagnosis and surgical tactics in this disease. result of a comprehensive study, a diagnosis of total intestinal polyposis was established. After conservative treatment she was discharged in a relatively satisfactory condition.

On 8 January 2012 she was repeatedly hospitalized for acute intestinal obstruction, with signs of moderate anemia in the surgical department of the RCEME of the Andijan branch. The laparotomy, reduction of jejuno-jejunal intussusceptum was made. She was also found to have polyposis of the small intestine without intervention on it. She was discharged from the hospital on 15.01.2012 year in a relatively satisfactory condition. Two days prior to admission she complained of cramping and rumbling all over the abdomen, nausea, vomiting, gas and stool retention, as well as lack of appetite, general weakness and malaise.

She was admitted to the Department of Clinical Surgery No.3 on 02.02.2012.

On admission the patient's condition was of moderate severity. There were signs of retardation of physical development. Height $162 \mathrm{~cm}$, weight $47 \mathrm{~kg}$. The skin and visible mucous were of pale color. Around the upper and lower lips there was 
dark brown pigmentation with a diameter of 1-2$3 \mathrm{~mm}$, lined in one row at the border of the transition to the skin of the labial surface (Fig. 5).

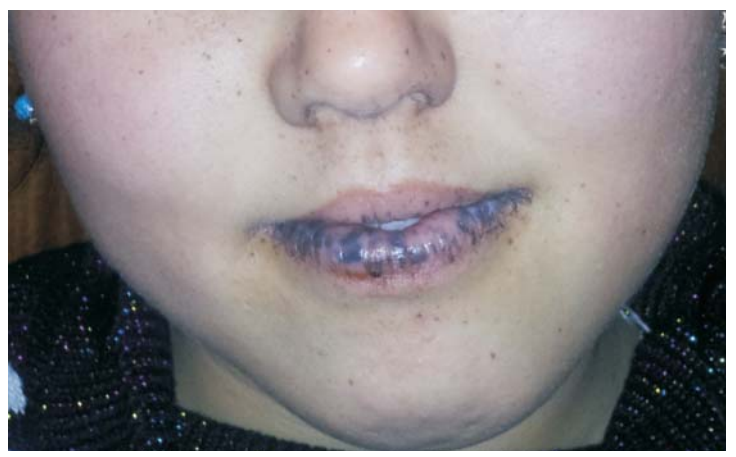

Fig. 5. Patient B. There are around upper and lower lips dark-brown color pigmentations with diameter 1-2-3 $\mathrm{mm}$, covered in one row on border of the transition to skin of the labial surface

Tongue was wet and. Respiration rate was 20 breaths per minute. Above the lungs breathing is carried out in all departments, no wheezing. Heart rate was 100 beats per minute, blood pressure 110/70 mmHg. The abdomen was of usual configuration, with a postoperative scar in the mid-midline, the abdomen was soft on palpation, moderately tender in all departments. Symptoms of peritoneal irritation were absent. Her last defecation was 4 days ago. Flatulence. Urination was without difficulties, regular.

ECG findings: sinus tachycardia. The normal position of the electrical axis of the heart. Diffuse changes in the myocardium.

Plan radiography of the chest and abdomen: the pulmonary fields were clean, the sinuses were not blocked, the heart and aorta were without abnormalities. There were no signs of free gas in the abdominal cavity; there were single cups of Kloyber. Urine tests did not show any pathology.

Complete blood count: erythrocytes 3.0x 1012, hemoglobin $74 \mathrm{~g} / \mathrm{l}$, hematocrit count 26, CP - 0.7, leucocytes 4.2×109, ESR - 5 ì ì /h.

Diagnosis: Peutz-Jeghers' syndrome.

The patient underwent complex preoperative preparation (nasogastric probe with gastric lavage, parenteral administration of electrolytes, preventive antibiotic therapy, etc.).

On 03.02.2012 at 10.14 pm middle-median laparotomy was performed with excision of the old postoperative scar under endotracheal anesthesia after appropriate treatment of the skin with hemostasis along the wound.

Revision of the abdominal organs showed the presence of 3 and 4-cylinder jejuno-jejunal intussuscepta. After their reduction, the viability of the intestines was preserved. Palpation in these places detected glandular polyps on the pedicle with a diameter of 2.0 to $3.5 \mathrm{~cm}$, which contributed to the formation of intussuscepta. Excision of polyps was performed by longitudinal enterotomy, followed by closure of the bowel defect in the transverse direction, in order to avoid narrowing of its lumen.

Upon further revision, the presence of a multiple polyps was established in the jejunum and single polyps in the ileum with a diameter of $0.7-$ 1.0 to $3.0-4.0 \mathrm{~cm}$, which could further prevent the passage of its contents and the absorption of nutrients. In addition, enterotomy, excision of polyps and suturing of the defect were performed in 22 places in the same way. The patient was administered nasogastroduodenal decompression probe, expansion of the anus according to Payr, as well as thorough reorganization of the abdominal cavity with antiseptic solutions. Drainage of the abdominal cavity was performed for control. Laparotomy wound was closed by layer-by-layer suturing with aseptic dressing.

Gross specimen: glandular-villous polyps of the small intestine in the amount of 42, with a diameter of $1.5-2.0$ to $3.5-4.0 \mathrm{~cm}$. Of them, 3 polyps had signs of hemorrhage. Histological findings: smooth muscle polyps.

The postoperative period was uneventful, without complications. On 15.02.2012 the patient was discharged from the hospital in a satisfactory condition. At the same time, the patient was recommended a follow-up every 6 months.

Results. After reviewing the literature data and assessing this case, we concluded that there was a triad of signs of Peutz-Jeghers' syndrome: perioral hyperpigmentation, multiple small intestinal polyposis (mostly jejunum) and the presence of intussuscepted jejuno-jejunal obstruction. Moreover, when performing the first operation (reduction of intussusception), its cause was not eliminated. This contributed to the recurrence of acute intestinal obstruction in the form of intussusception, as well as preservation of signs of retardation of physical development and chronic anemia of moderate severity.

The patient was recommended sparing diet, restricting physical exertion, medication, astringent agents (bismuth nitrate). Pigmentation of lips was treated with laser light. Follow-up every 6 month for 3 years.

After 1 year her height was $162 \mathrm{~cm}$, weight $47 \mathrm{~kg}$. She was in satisfactory condition, without signs of retardation of physical development. Function of the bowels was normal. 


\section{Conclusions}

Abdominal surgeon should know about Peytz-Jeghers' syndrom to provide correct diagnosis and timely give qualified emergency surgical treatment, completely remove polyps, promote normalization of intestinal function, prevent relapsing of intussusception and obstruction of the intestine.

\section{References:}

1. Ivashkin, V. Q̀, Lapina, Ò L. (2006). Rational pharm therapy of the alimentary tract diseases. Ì .: Litter, 552.

2. Komarov, F. I., Grebenev, À. L., Burkov, S. G. (1996). Diseases of pancreas, intestine, system illnesses with dysfunction of alimentary tract. M.:Meditsina, 572-605.

3. Kaybisheva, V. Î ., Ivashkin, V.Ò, Baraskaya, Å.Ê. (2011). Syndrome Peyts-Egers: Common literature and written own clinic researches. Rubric: Exchanging experiences RJGGK, 21, (2), 54-61.

4. Amos, C. I., Keitheri-Cheteri, M. B. (2004). Genotype-phenotype correlations in PeutzJeghers'syndrome. J. Med. Genet, 41, 27-360.

5. Basak, F., Kinaci, E. (2010). Multiple intestinal intussusceptions in Peutz-Jeghers'syndrome: a case report. Acta Chir. Belg, 110, (1), 93-94.

6. Calva, D. (2008). Hamartomatous polyposis syndromes. Surg. Clin. North Am, 88, 779-817.

7. Jansen, M., Leng, W., Baas, A. F. (2006). Mucosal prolapse in the pathogenesis of Peutz-Jeghers polyposis. International journal of gastroenterology and gepatology. Gut, 55, 1-5.

Received: 01-Sep. - 2017

Accepted: 12-Aug. - 2018 